\title{
A model for the identification of tropical weather systems over South Africa
}

\author{
LL Dyson* and J van Heerden \\ Department of Geography, Geoinformatics and Meteorology, University of Pretoria, Pretoria 0001, South Africa
}

\begin{abstract}
South Africa forms the southern end of Africa with its northern boundary at approximately $22^{\circ} \mathrm{S}$ and the southern-most point, Cape Agulhas, at approximately $35^{\circ} \mathrm{S}$. During most of the year atmospheric circulation over South Africa, especially the central and southern regions, is dominated by extra tropical weather systems such as cut-off lows, cold fronts and the ridging Atlantic Ocean High. Weather forecasters in South Africa are trained on and experienced in forecasting rainfall from these systems. During late summer weather systems from the tropics invade the northern regions of South Africa. Because tropical weather systems only appear during three or four months of the year weather forecasters often lack the experience to identify them timeously. Invading tropical weather systems are often associated with heavy rainfall and flooding (February 1988, February 1996, February 2000). It is very important that forecasters identify these tropical systems and apply appropriate forecasting techniques. Prior to this research no objective system to classify tropical systems and to pinpoint areas of significant to heavy rainfall was employed locally. This research resulted in the model for the identification of tropical weather systems (MITS). MITS has five components based on the atmospheric dynamics important for the development of convective rainfall from tropical systems. The application of MITS is detailed in a case study of heavy rainfall from a tropical system over the country on 8 February 2000. MITS identified the tropical nature of the system and successfully located areas of convective rainfall. MITS is available on the software system PCGRIDDS currently in operational use in South African forecasting offices. It operates on the prognostic fields generated by the South African Weather Service limited-area model Eta. Trial runs of MITS in the Central Forecasting Office of the South African Weather Service (SAWS) provided a positive response from weather forecasters and a full operational implementation is imminent.
\end{abstract}

\section{Introduction}

The subtropical high-pressure belt dominates the weather over Southern Africa, which is, except during a few winter months, split by the continent to become the Atlantic Ocean High $(\mathrm{AOH})$ and the Indian Ocean High (IOH). Variations in position and intensity of the two high-pressure systems play an important role in the rainfall distribution over South Africa (Shulze, 1965). The mid-latitude westerly circulation, extending northwards to, and in association with, these two high-pressure systems, controls to a large extent, the weather of South Africa (De Coning, 1997). During the summer months, as the high-pressure systems migrate southwards, the influence of the westerly circulation is diminished.

In the summer the intertropical convergence zone (ITCZ), identified by large convective cloud structures, moves southwards to approximately $17^{\circ} \mathrm{S}$ (Taljaard, 1994) bringing tropical weather to South Africa's northern regions. Van Heerden and Taljaard, contributing to Karoly and Vincent (1998), suggested that during this time of the year tropical weather systems invade Southern Africa in the form of tropical cyclones, tropical lows and easterly waves. They described how a tropical low over the interior of Southern Africa could be identified on loops of half-hourly geostationary satellite images by locating the low-level cyclonicand anti-cyclonic upper tropospheric circulation as depicted by the cloud motion. Tropical systems generally move from east to west over the subcontinent rarely reaching the African west coast. Tropical cyclones degenerating to tropical lows favour the large river valleys in their westward migration. Crimp et al. (1997), researching the link between the tropical and temperate circulation

* To whom all correspondence should be addressed.

푱 012 4202469; fax: 012 4203284; e-mail: ldyson@postino.up.ac.za Received 13 August 2001; accepted in revised form 5 June 2002. systems, gave a thorough description and stressed the importance of this link referred to as the tropical temperate trough (TTT) in producing rainfall over South Africa. They estimated that approximately $39 \%$ of the mean annual rainfall could be attributed to the TTT. The TTT is easily identified on satellite imagery as long cloud bands linking the tropical convective systems to the midlatitude (temperate) frontal systems. Lindesay and Jury (1991) suggested that the weather system responsible for heavy rainfall over the central interior of South Africa during February 1988 was a tropical-temperate trough. Triegaardt et al. (1991), on the other hand, made a detailed analysis of the dynamics of this weather system and stressed the tropical nature of the atmospheric circulation during this event. Taljaard (1985) in discussing the cut-off low (COL) provided a brief description of the tropical easterly low over Southern Africa, specifically referring to the higher than normal upper tropospheric temperatures above the low. Preston-White and Tyson (1993) proposed that an easterly wave could be distinguished from an easterly low by considering the level of maximum wind divergence. In the latter case they found that the wind divergence frequently occurred at higher levels in the troposphere.

Heavy rainfall and flooding are not rare over South Africa. Viljoen, cited in Alexander and Van Heerden (1991), lists 184 noteworthy flood events during the years from 1911 to 1988 . Close to $30 \%$ of these events occurred over KwaZulu-Natal and $42 \%$ over the four northern and central provinces of South Africa. Some 67\% of all these flood events occur during the summer rainfall season (October to March). Research results of Alexander and Van Heerden (1991) indicated that the month with the highest frequency of floods is February. They also claimed a marked increase of serious floods from 1970 to 1990 and postulated that the frequency of serious flood events may in fact be increasing. These results are echoed by recent research results of Poolman (1999). He found that most heavy rainfall events occurred during the summer months 
with the highest frequency in January and February. He also concluded that the eastern and central parts of South Africa had the largest number of days with heavy rainfall.

Considering the high frequency of heavy rainfall events over the eastern and northern parts of South Africa, in summer, it becomes imperative to develop better forecasting techniques to identify and predict tropical weather systems. Numerous research results exist which describe heavy rainfall from tropical weather systems over Southern Africa, markedly those by Alexander and Van Heerden (1991), Dyson and Van Heerden (2001), Lindesay and Jury (1991) and Triegaardt et al. (1991). Unfortunately research results on the forecasting techniques best suited for tropical weather systems have largely been neglected in South Africa. Disappointingly few recent research results are available on forecasting techniques in Southern Africa, one exception being De Coning (1997) who described how isentropic analysis could be used as a forecasting tool in South Africa. Isentropic analysis was applied with some success in identifying heavy rainfall areas for the heavy rainfall event during February 1996. In fact very few local researchers provided general rules to differentiate between tropicaland temperate weather systems. A few, notably Taljaard (1985) and Triegaardt et al. (1991) stressed the importance of identifying circulation features typical of tropical weather systems.

Research on tropical systems continued in countries to the north of South Africa, so much so that the years 1940 to 1970 were dubbed the golden period of African tropical meteorology. Meteorologists of the so-called British school in East Africa, the Rhodesias (now Zimbabwe and Zambia) as well as the French school in equatorial western Africa, all researched the circulation systems favouring rainfall over tropical and subtropical Africa (Van Heerden and Taljaard contributing to Karoly and Vincent, 1998). Forsdyke (1949) expressed the hope that tropical meteorology in Africa will develop faster and further after the Second World War. History has, alas, proven him wrong.

Forsdyke (1949) reasoned that forecasting in the tropics requires different techniques from those employed in temperate latitudes. The quasi-geostrophic theory described by Holton (1992), is less amenable in the tropics because the Coriolis force becomes neglible with the result that the flow generally crosses the isobars. Forsdyke (1949) also suggested that streamline analysis be used to research tropical circulation and be employed to prepare forecasts. Thompson (1957) and Riehl (1979) supported this approach. At present streamline analysis is used in many countries where tropical weather systems are common. Forecasters in South Africa, however, seldom use streamline analysis.

\section{Typical tropical circulation features}

Researching tropical weather systems Riehl (1979) found that upper air winds, surface pressure anomalies, $12 \mathrm{~h}$ and $24 \mathrm{~h}$ pressure changes, $24 \mathrm{~h}$ changes in the height of upper isobaric surfaces and a plot of temperature and specific humidity are all essential parameters and tools required to predict tropical weather. Forsdyke (1949) and Thompson (1957) determined that when the environmental lapse rate is greater than the saturated adiabatic lapse rate and high levels of humidity exist up to the freezing level, widespread or general precipitation is likely. Riehl (1979) also explained how a vertical profile of total static energy (TSE) identifies an unstable tropical atmosphere. In South Africa Harrison (1988) and Triegaardt et al. (1991) researched rain-producing weather systems over South Africa and found that the vertical profile of TSE could be linked to extensive tropical rainfall.

It should be recognised that case studies of tropical systems are completed long after the event and in a research environment. Weather forecasters, however, operate under considerable stress and have to meet tight deadlines. In order to provide the weather forecaster with a practical and operational tropical weather identification system, running in real time, Dyson (2000) developed and demonstrated the model for the identification of tropical weather systems (MITS). MITS uses general circulation model (GCM) data, which are available, in real time, to the weather forecaster. MITS can also be useful in the production of a timely and reliable rainfall forecast by identifying areas where tropical convection can be expected. In order to make MITS accessible to an operational meteorologist it is displayed using the graphical display package PCGRIDDS currently used operationally by the South African Weather Service (SAWS).

\section{Components of MITS}

Southern Africa is characterised by a moderately elevated plateau, for the greater part rising to over $1000 \mathrm{~m}$ above sea level and to more than 1500 m over extensive areas (Taljaard, 1994). For this reason it is the practice in the forecasting offices in South Africa to convert surface pressure measured at synoptic weather stations to the height of the $850 \mathrm{hPa}$ pressure level measured in geopotential meter (gpm). These gpm heights are plotted on synoptic weather maps. The $850 \mathrm{hPa}$-geopotential heights are also available from numerical weather prediction (NWP) models. It therefore made sense to develop MITS specifically for the interior of South Africa much of which lies close to the $850 \mathrm{hPa}$ level.

MITS has five basic components or criteria: First the vertical displacement (integrity) of low- and high-pressure systems with height. Second the relationship between upper tropospheric temperatures and large-scale synoptic systems. Third the existence of a moist diverging high in the upper troposphere. Fourth is high average values of total static energy (TSE) throughout the troposphere. Fifth the conditional instability of the atmosphere as determined from the vertical distribution of TSE.

It is a well-established fact that upward motion in the lower and middle troposphere is of paramount importance for the production of widespread rainfall. The geographical areas of widespread upward motion are located and linked to these five components by MITS. The final and probably most important product of MITS is to create a single field, which indicates where rainfall in a tropical atmosphere is likely to occur.

\section{Vertical integrity of low and high-pressure systems}

The coordinate system used in the text is the so-called $(x, y, p, t)$ system with $\mathrm{x}$ the west/east coordinate, $\mathrm{y}$ the south/north coordinate, $\mathrm{p}$ the pressure coordinate and the time.

Holton (1992) defines a barotropic atmosphere as one in which the density is a function of pressure alone. This means that isobaric surfaces are also surfaces of constant temperature so that:

$$
\bar{\nabla}_{p} T=0
$$

where:

$$
\begin{aligned}
\bar{\nabla}_{p} & =\bar{i} \frac{\partial}{\partial x}+\bar{j} \frac{\partial}{\partial y} \text { and } \\
\mathrm{T} & =\text { temperature. }
\end{aligned}
$$

If the horizontal gradient vector of the average column temperature is zero then the thermal wind will be zero. The thermal wind is defined as the vertical shear of the geostrophic wind and can be expressed by: 


$$
\bar{V}_{T}=\bar{V}_{g}\left(p_{1}\right)-\bar{V}_{g}\left(p_{0}\right)
$$

where:

$$
\begin{aligned}
& \bar{V}_{T}=\text { the thermal wind and } \\
& \bar{V}_{g}=\text { the geostrophic wind at pressure levels } p_{1} \text { and } p_{0}\left(p_{1}<p_{0}\right)
\end{aligned}
$$

When the thermal wind is equal to zero the geostrophic wind will not change with height. This also means that in a barotropic atmosphere the horizontal component of the gradient of geopotential remains constant with height. Synoptic-scale high- and low-pressure systems will in this ideal situation "stand upright" with height.

Holton (1992) further states that barotrophy provides very strong constraints on the motion in a rotating fluid and is in fact never achieved in the atmosphere. Nevertheless in a tropical atmosphere the circulation will tend towards this ideal situation. Holton (1992) also detailed the vertical integrity, up to $400 \mathrm{hPa}$, of low-pressure systems, associated with the precipitation zone of equatorial wave disturbances in the western Pacific Ocean. MITS was designed to look for a low-pressure system, which stands approximately upright with height from the surface $(850 \mathrm{hPa})$ up to the $400 \mathrm{hPa}$ level.

In the real tropical atmosphere strong surface and middle tropospheric convergence occurs in association with the "upright" low-pressure system. This convergence in turn results in upward motion and if adequate water vapour is available convective cloud or so-called "hot towers" will develop. Riehl (1979) explains the process by which the hot towers act as energy tubes through which energy from the lower troposphere is transported to the upper troposphere where it is distributed horizontally by the upper air divergence. The condensation releases a large amount of latent heat, which is in turn responsible for above-normal upper tropospheric temperatures (Triegaardt et al., 1991). Holton (1992) shows that the geopotential thickness of a layer is directly proportional to the average column temperature with the result that an upper tropospheric high-pressure system forms above the surface low. The latent heat release therefore, quickly results in a warm core (high pressure) developing above the lower level low (Taljaard, 1985).

The 1st component of MITS therefore requires:

The low-pressure system must stand upright from 850 to $400 \mathrm{hPa}$ and should be displaced by a ridge of high pressure at the $200 \mathrm{hPa}$ level.

\section{Average column temperatures in the 500 to $300 \mathrm{hPa}$ layer}

As detailed above latent heat release leads to above-average column temperatures and an upper tropospheric high above the surface low pressure system. The average column temperatures in the 500 to $300 \mathrm{hPa}$ layer are fundamental for the identification of tropical weather systems. No specific threshold is set for the average 500 to $300 \mathrm{hPa}$ temperatures in a tropical circulation system but the column temperatures should be compared to the surrounding areas in order to identify a warm cored system. It should be remembered that this field alone does not identify a tropical circulation system as an upper tropospheric high-pressure system will necessarily be associated with warm temperatures. In addition the absence of a horizontal temperature gradient of the 500 to $300 \mathrm{hPa}$ average column temperatures indicates a barotropic atmosphere. However, true barotrophy never occurs in the real atmosphere. A weak upper tropospheric temperature gradient can nevertheless be used to identify a 'tropical atmosphere'.

The 2nd component of MITS requires:
A core of high average column temperatures should be present in the 500 to $300 \mathrm{hPa}$ layer above or near the surface low pressure system.

\section{Moist diverging high in the upper troposphere}

A fundamental component in the development of the tropical upper tropospheric high-pressure system is the release of latent heat through condensation of water vapour. Maintenance of an upper tropospheric high therefore requires a high moisture content below the upper high-pressure system. Precipitable water is often used to determine atmospheric moisture content. Huschke (1959) defines precipitable water $(\mathrm{W})$ as the total mass of water contained in a vertical atmospheric column if all the water vapour in the column were to condense. In this paper this definition applies but the precipitable water is calculated for a vertical column bounded by the $850 \mathrm{hPa}$ to $300 \mathrm{hPa}$ levels using:

$$
W=\frac{1}{g} \int_{p_{1}}^{p_{2}} q d p
$$

where:

$$
\begin{aligned}
& g=9.8 \mathrm{~ms}^{-2} \\
& p_{1}=300 \\
& p_{2}=850 \mathrm{hPa} \\
& q=\text { mixing ratio. }
\end{aligned}
$$

The 850 and $300 \mathrm{hPa}$ pressure levels bound the vertical column.

Analysis conducted by Dyson (2000) determined that precipitable water values greater than $20 \mathrm{~kg} \cdot \mathrm{m}^{-2}(=20 \mathrm{~mm}$ rain $)$ are required to maintain a tropical upper thermal high. Values of precipitable water, greater than $20 \mathrm{~kg} \cdot \mathrm{m}^{-2}$ in the same geographical position as the $200 \mathrm{hPa}$ high-pressure system indicate a tropical system.

Dines compensation (Holton, 1992) requires that the upper tropospheric high maintain significant horizontal wind divergence a few kilometres below the tropopause, i.e. the 200 to $300 \mathrm{hPa}$ levels. This divergence removes air horizontally in the upper troposphere. It is because of this wind divergence that the vertical integrity of the tropical system can be maintained. Without the upper tropospheric divergence the system would fill up because of the lower level convergence and latent heat release. Synoptic scale values of horizontal wind divergence on any pressure level are in the order of $10^{-6} \mathrm{~s}^{-1}$ and are very sensitive to slight perturbations in the wind field (Holton, 1992). In MITS the average wind in the 200 to $300 \mathrm{hPa}$ layer is used to calculate the horizontal divergence in order to smooth small pertubations in the wind field.

The 3rd MITS component demands:

Precipitable water values in the 850 to $300 \mathrm{hPa}$ layer should exceed $20 \mathrm{~kg} \cdot \mathrm{m}^{-2}$ and be in the same geographical position as the $200 \mathrm{hPa}$ ridge or high-pressure system and must be accompanied by upper tropospheric wind divergence.

\section{Average total static energy (TSE)}

The equivalent potential temperature as defined by Holton (1992) is a measure of the moisture content of the surface air as well as the environmental lapse rate. It is common practice for forecasters in South Africa to use the equivalent potential temperature to pinpoint transition zones between differing air masses by searching for tight gradients of equivalent potential temperature. This method is used with considerable success in identifying and forecasting cold fronts invading South Africa from the south-west. Holton (1992) states that an alternative to the equivalent potential temperatures is the 
total static energy (TSE) (also referred to as moist static energy). This is especially so when convection is studied. TSE is defined as the total energy in an atmospheric parcel of air, neglecting the small amount of kinetic energy (Triegaardt et al., 1991). TSE is computed by:

$$
T S E=C_{p} T+g z+L q
$$

where:

$$
\begin{array}{ll}
C_{p} & =\text { the specific heat of dry air } \\
z & =\text { the geopotential height in metre }(\mathrm{gpm}) \\
L & =\text { the latent heat of condensation } \\
q & =\text { the water vapour mixing ratio. }
\end{array}
$$

The first term on the right-hand side of the equation represents the enthalpy, the second term the geopotential and the third term the latent energy. In an atmosphere where higher than normal upper tropospheric temperatures occur, as is the case of an air mass with tropical characteristics, the contribution of the enthalpy will increase the TSE values. Higher geopotentials, generally found in the upper troposphere in tropical weather systems, will also increase the TSE values. The high moisture content found in the lower troposphere in tropical weather systems increases the TSE values through the latent heat term.

In MITS the average TSE is computed for the 850 to $300 \mathrm{hPa}$ layer. Experimental results indicated that TSE values greater than $330 \times 10^{3} \mathrm{~J} \cdot \mathrm{kg}^{-1}$ are indicative of tropical circulation over Southern Africa (Dyson, 2000).

The 4th component of MITS becomes: Average total static energy (TSE) in the 850 to $300 \mathrm{hPa}$ layer should exceed $330 \times 10^{3} \mathrm{~J} \cdot \mathrm{kg}^{-1}$. Tight horizontal gradients of TSE also indicate a zone of air mass change.

\section{Deep cumulus convection and vertical motion}

As was stated above a continental tropical weather system over South Africa is characterised by an upright low-pressure system from 850 to $400 \mathrm{hPa}$. Horizontal wind convergence will therefore occur up to $400 \mathrm{hPa}$ and will be replaced by strong wind divergence above that.

Vertical motion ( $w=\frac{d z}{d t}$ ) is the time derivative of the vertical coordinate $(\mathrm{z})$ in the $(\mathrm{x}, \mathrm{y}, \mathrm{z}, \mathrm{t})$ system. Omega is the time derivative of the vertical coordinate in the $(\mathrm{x}, \mathrm{y}, \mathrm{p}, \mathrm{t})$ system where $\omega=\frac{d p}{d h}$.

Holton (1992) indicated how the relationship between onkega and vertical motion may be approximated by $\omega=-g \rho \mathrm{w}$. The continuity equation (Holton, 1992) expresses the relationship between horizontal wind divergence and the partial derivative of omega with pressure: $\frac{\partial \omega}{\partial p}=-\bar{\nabla}_{p} \bullet \bar{V}$

If $\bar{\nabla}_{p} \bullet \bar{V}<0$ (convergence) then $\frac{\partial \omega}{\partial p}>0$ which means that $\omega$ decreases (increases) with height (pressure). When convergence occurs in the lower and middle troposphere $\omega$ decreases with height, which means that, because of the negative relationship between vertical motion and $\omega$, upward motion must increase with height. At levels above $400 \mathrm{hPa} \omega$ increases with height in association with the upper tropospheric divergence.

The interior of South Africa is approximately $1500 \mathrm{~m}$ above sea level and this means that the $700 \mathrm{hPa}$ level is approximately $1500 \mathrm{~m}$ above the land surface and can still be considered representative of the lower troposphere. The $700 \mathrm{hPa}$ level is also close to the summer convective cloud base level. An important function of MITS is to isolate areas where upward motion exists from $700 \mathrm{hPa}$ to $400 \mathrm{hPa}$.
The vertical profile of TSE values is used to determine the conditional instability of the atmosphere. Harrison (1988), amongst others, indicated that a conditional unstable atmosphere is required for deep cumulus convection. To determine the level of conditional instability (LCI) the following formula is used:

$$
L C I=T S E_{850}-T S E_{i}
$$

where i varies between $700 \mathrm{hPa}$ and $400 \mathrm{hPa}$. For the atmosphere to be considered conditionally unstable up to $400 \mathrm{hPa}$ (a requirement of MITS) the LCI must remain positive for $\mathrm{i}=700 \mathrm{hPa}$ to $400 \mathrm{hPa}$. Experimental results obtained for this paper indicated that when this condition is met together with upward motion in the 700 to 400 $\mathrm{hPa}$ layer and the precipitable water in the 850 to $300 \mathrm{hPa}$ layer also exceeds $20 \mathrm{~kg} \cdot \mathrm{m}^{-2}$, then conditions are favourable for the development of extensive convective precipitation.

And finally the 5th MITS component is:

Upward motion to be present from 700 to $400 \mathrm{hPa}$, the atmosphere should be conditionally unstable up to $400 \mathrm{hPa}$ and precipitable water values should also exceed $20 \mathrm{~kg} \cdot \mathrm{m}^{-2}$.

\section{Data}

MITS was developed from research on historic heavy rainfall events caused by tropical weather systems using National Center for Environmental Prediction (NCEP) data. Dyson (2000) provided a detailed description of MITS development in investigating the heavy rain-producing weather systems during February 1988 and January 1981. The NCEP data were applied in order to identify the dynamic characteristics typical of tropical weather systems. Unfortunately these data are of little use in a forecasting environment where prognostic fields from numerical weather prediction must be analysed in order to create a forecast. It was therefore decided to test MITS on the prognostic fields of the limited area model Eta which is currently operational in the SAWS. Eta has a horizontal resolution of half a degree (approximately $50 \mathrm{~km}$ ) and has 38 levels in the vertical. Eta data are available on the display system PCGRIDDS in the geographical area bounded by $10^{\circ} \mathrm{S}$ to $50^{\circ} \mathrm{S}$ and $10^{\circ} \mathrm{W}$ to $55^{\circ} \mathrm{E}$. A comprehensive description of the Eta model is provided by Mesinger et al. (1988). In this case study the standard pressure levels $850,700,600,500,400,300,250$ and $200 \mathrm{hPa}$ are extracted from the Eta model output for MITS application. The rainfall data were obtained from the SAWS.

\section{MITS and the heavy rainfall of 8 February 2000}

\section{Synoptic circulation 8 February 2000}

February 2000 will be remembered for the devastating floods, which occurred over the Northern Province of South Africa and central Mozambique. Hundreds of people lost their lives and the raging water displaced tens and thousands of people. Most of the rainfall occurred during two periods namely 5 to 10 February and 22 to 25 February 2000. During both periods the severe rainfall was caused by a tropical weather system moving from east to west over the southern subcontinent (Dyson and Van Heerden, 2001). MITS was applied during both these heavy rainfall periods and in both cases identified the tropical nature of the atmospheric circulation. Due to the many figures generated on each day to illustrate MITS only results on 8 February 2000 will be detailed here. MITS was applied to the $12 \mathrm{~h}$ prognosis of the 00:00 UTC Eta model run on the $8^{\text {th }}$ and all the MITS results discussed here originated from these Eta prognostic fields and are valid for 12:00 UTC on the $8^{\text {th }}$. 


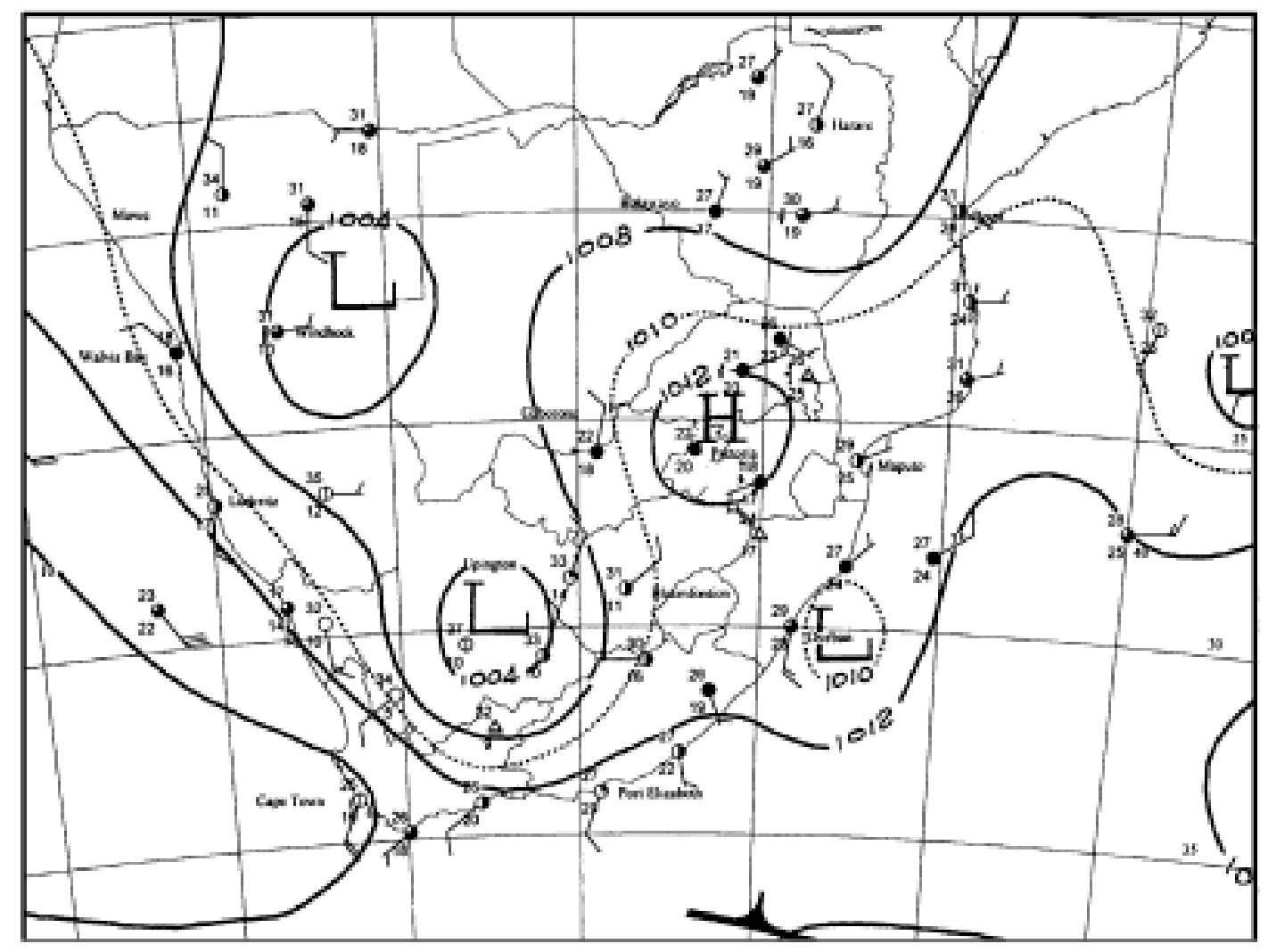

Figure 1

Sea level pressure in hPa at 1200 UT on 8 February 2000 (courtesy of the South African Weather Service)

On 8 February 2000 the surface tropical low pressure system was situated over the Namibia Botswana border, with a secondary low over the central interior of South Africa (Fig. 1). The highpressure system prevailing over the north-eastern interior of South Africa maintained an inflow of moist tropical air from the Mozambique Channel over the central and eastern interior of the country. Widespread and heavy rainfall occurred over Gauteng-, eastern parts of the Northwest- and western part of the Northern Provinces (shaded area in Fig. 7). On this day Germiston in Gauteng had $144 \mathrm{~mm}$, Stockpoort in the Northern Province 145 $\mathrm{mm}$ and Marico in the Northwest Province $155 \mathrm{~mm}$.

\section{MITS components}

Figure 2 represents the $850 \mathrm{hPa}, 700 \mathrm{hPa}, 500 \mathrm{hPa}, 400 \mathrm{hPa}$ and 200 $\mathrm{hPa}$ geopotential height fields. The fact that the low is "standing upright" is clearly evident. Near the centre of the low over Botswana the 850,700 and $500 \mathrm{hPa}$ contours are nearly parallel. Figures 2D and $2 \mathrm{E}$ depicts the $400 \mathrm{hPa}(200 \mathrm{hPa})$ geopotential heights. A broad weak trough is present at $400 \mathrm{hPa}$ in the same geographical position as the low illustrated in Fig. 2 (A to C). However, at $200 \mathrm{hPa}$ a closed high-pressure system lies right above the low on the lower levels, which is typical of tropical circulation systems. Figure 2 clearly illustrates that the first component of MITS is satisfied.

Figure 3 depicts the average column temperatures in the 500 to $300 \mathrm{hPa}$ layer. The highest temperatures $\left(-14.5^{\circ} \mathrm{C}\right)$ occur over central Botswana. A comparison with Fig. 2E shows that this core of high temperatures lies in the same geographical position as the $200 \mathrm{hPa}$ high. Comparing the temperature gradient over the Northern Cape Province with the temperature gradient over the Northern
Province and Mozambique it is clear that the air in circulation over the eastern parts of the subcontinent is typical of a tropical circulation system.

Figure 4 shows the precipitable water in the 800 to $300 \mathrm{hPa}$ layer with the dashed contours indicating values greater than $20 \mathrm{~kg} \cdot \mathrm{m}^{-2}$. Comparing Figs. 2E, 3 and 4 it is clear that the high values of precipitable water overlap the position of the $200 \mathrm{hPa}$ high pressure. Wind divergence occurs over the central and eastern parts of the $200 \mathrm{hPa}$ high coincident with the high values of precipitable water. Both the 2nd and 3rd MITS components are clearly satisfied.

The average total static energy (TSE) is depicted in Fig. 5. Over most of the country TSE values are greater than $330 * 10^{3} \mathrm{~J} \cdot \mathrm{kg}^{-1}$. The dashed lines indicate values higher than $335 * 10^{3} \mathrm{~J} \cdot \mathrm{kg}^{-1}$ with maximum values of $337 * 10^{3} \mathrm{~J} \cdot \mathrm{kg}^{-1}$ over Gauteng and the Northwest Provinces. The tight gradient of TSE over the central interior is a clear indication of the change of the properties of the air mass towards to the south and west. The high TSE values roughly coincide with heavy rainfall on this day satisfying the fourth MITS component.

The arrows in Fig. 6 indicate areas where the atmosphere is conditionally unstable up to $400 \mathrm{hPa}$ encouraging deep cumulus convection. However, conditional instability also occurs in baroclinic circulation systems and this factor alone cannot be used to determine the tropical nature of a weather system. The dashed contours on Fig. 6 indicate those areas where upward motion exists in the column bounded by the $700 \mathrm{hPa}$ and $400 \mathrm{hPa}$ levels. Where the upward motion field overlaps the arrows (conditionally unstable atmosphere) conditions are conducive for deep cumulus convection. In Fig. 4 the precipitable water values greater than $20 \mathrm{~kg} \cdot \mathrm{m}^{-2}$ are 
A

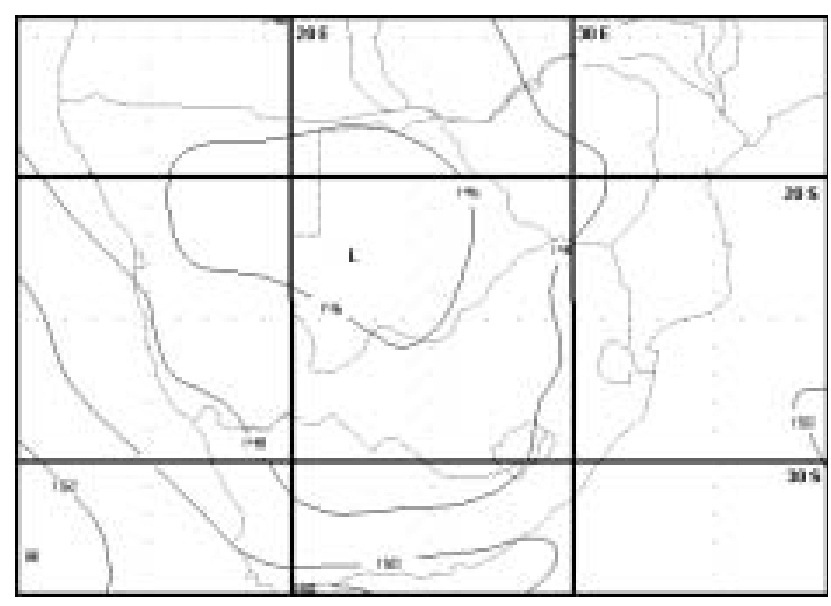

C

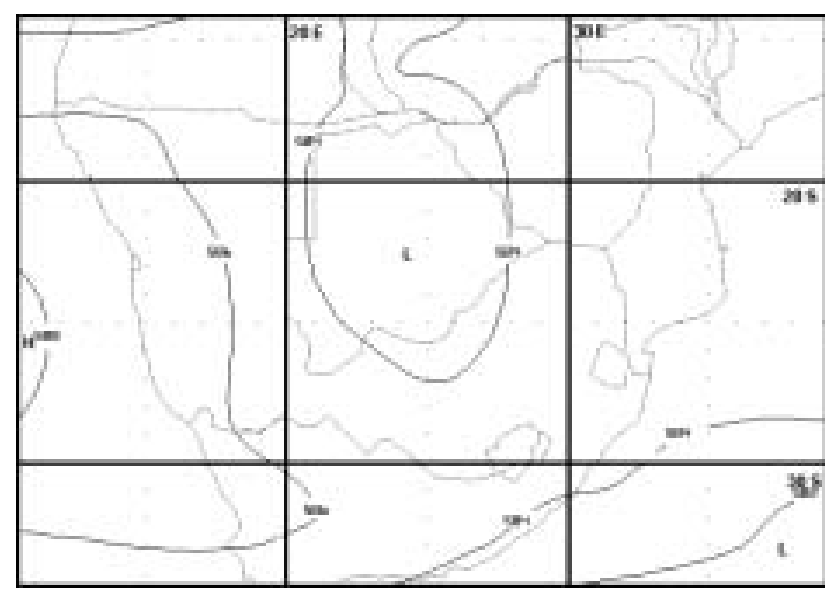

$\mathrm{E}$

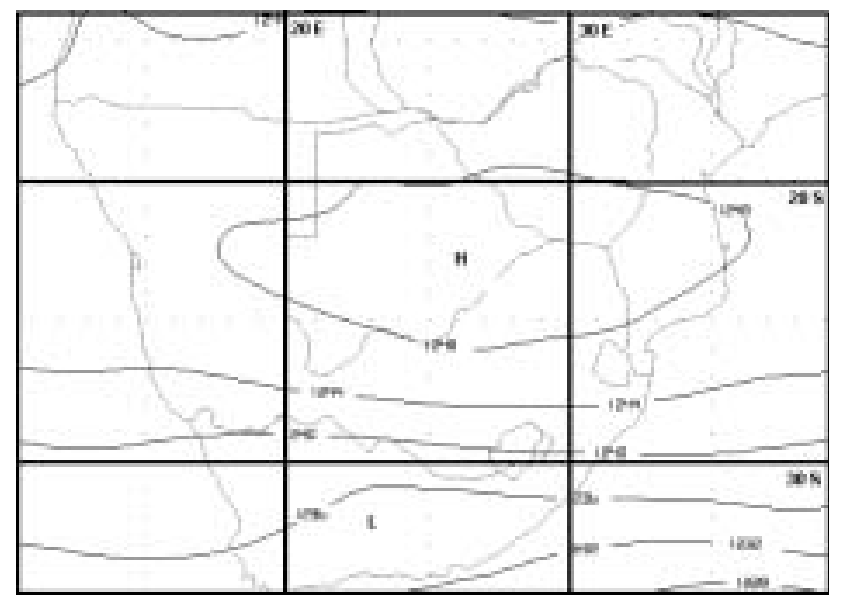

B

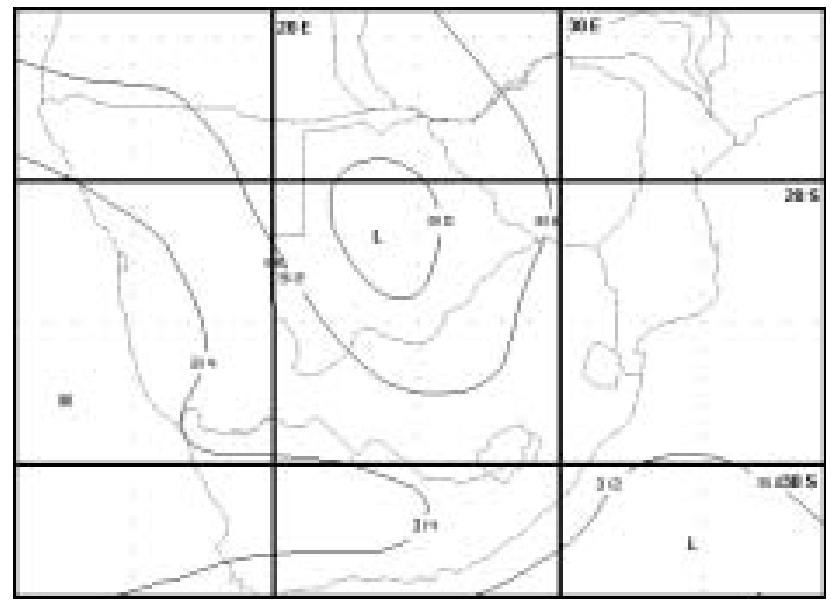

D

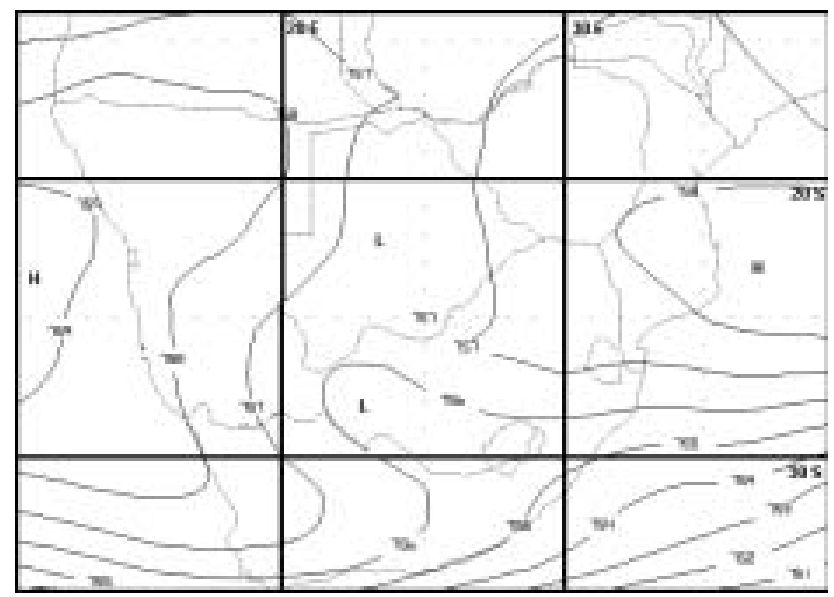

$\mathbf{F}$

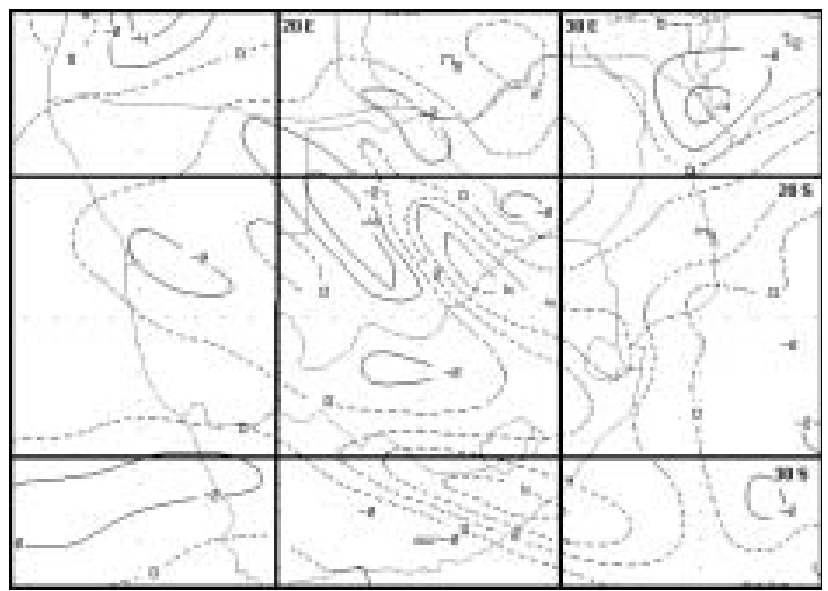

Figure 2

The topography of the 850, 700, 500, 400 and $200 \mathrm{hPa}$ pressure surfaces for 8 February 2000, shown in A, B, C, D and E respectively. The contours are labelled in geopotential decametre. Figure $F$ displays the average 200 to $300 \mathrm{hPa}$ wind convergence (solid lines) and divergence (dashed lines).

indicated and serve as a reminder that although atmospheric conditions are favourable for deep cumulus convection, no thunder showers will develop in the absence of sufficient water vapour.

\section{MITS results and actual rainfall}

The rectangles in Fig. 7 portray the area where precipitable water, conditional instability and vertical motion overlap while the geographical distribution of the actual recorded rainfall on 


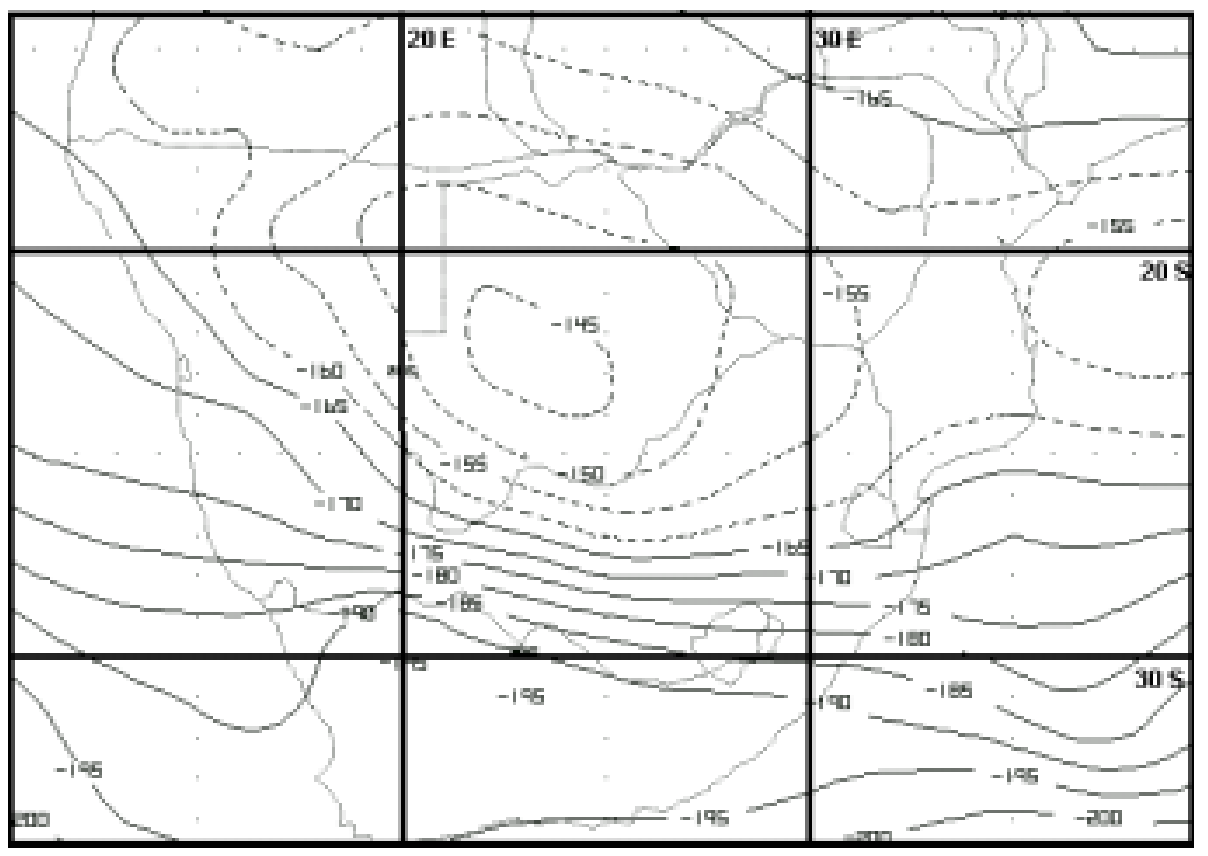

Figure 3

Average 500-300 hPa column temperatures on 8 February 2000. Temperatures are in ${ }^{\circ} \mathrm{C}$ Dashed lines indicate temperatures greater than $-16^{\circ} \mathrm{C}$

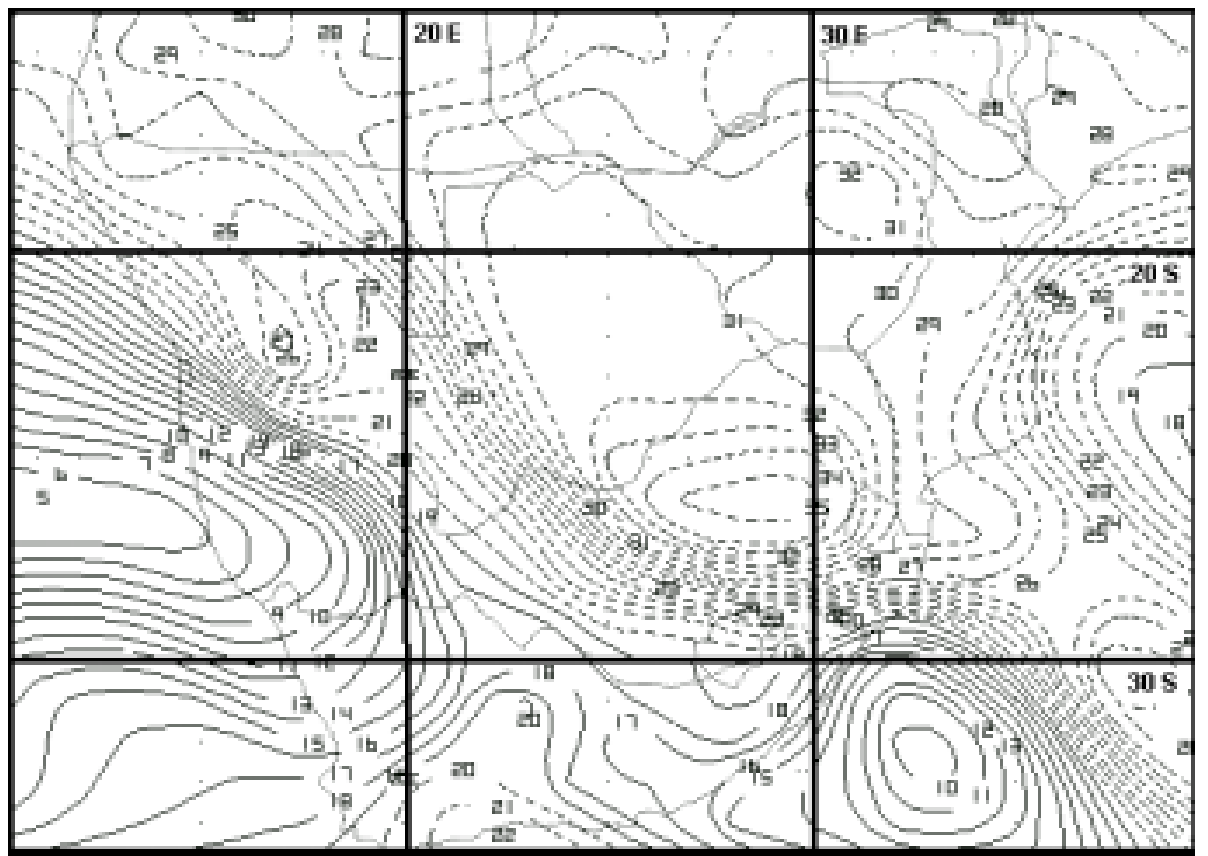

Figure 4

Precipitable water in the 850-300 hPa layer on 8 February 2000 in units of $\mathrm{kg} \cdot \mathrm{m}^{-2}$. Dashed lines indicate precipitable water values greater than

$20 \mathrm{~kg} \cdot \mathrm{m}^{2}$

8 February 2000 is displayed by the shaded area. The rainfall was recorded over $24 \mathrm{~h}$ (06:00 UTC on the $8^{\text {th }}$ to $06: 00$ UTC on the $\left.9^{\text {th }}\right)$ while the prognostic field is valid only for 12:00 UTC on the $8^{\text {th }}$. The inclusion of this graph therefore does not serve as a verification of the MITS forecast but gives some graphical representation of the accuracy of the predicted convective rainfall areas. Unfortunately no rainfall figures from neighbouring countries were available. Two areas were isolated by MITS. First is an extensive area over the north-eastern interior of South Africa extending to eastern and southern Botswana as well as into western Zimbabwe. The second area isolated by MITS is a small area over eastern Namibia. Within South Africa some rainfall occurred over the entire area isolated by MITS. Heavy rainfall, however, was confined to Gauteng, the eastern parts of the Northwest Province as well as the western parts of the Northern Province. Rainfall over the northern Free State and western Northwest Province was generally between 0 and $20 \mathrm{~mm}$.

The rainfall, which occurred over the southern Free State and eastern parts of the Northern Province, was not picked up by MITS. Careful analysis of Fig. 6 reveals that the level of deep convection extended up to $400 \mathrm{hPa}$ (a requirement of MITS) but vertical motion was absent in the 700 to $400 \mathrm{hPa}$ layer. The precipitable water values in the 850 to $300 \mathrm{hPa}$ column also remained below 20 $\mathrm{kg} \cdot \mathrm{m}^{-2}$ (Fig. 4). The widespread but generally light rainfall over this area was probably due to the secondary surface trough situated over the central interior (Fig. 1).

\section{Conclusions}

In a number of case studies by Dyson (2000) MITS identified the tropical weather systems, which moved over Mozambique and the 

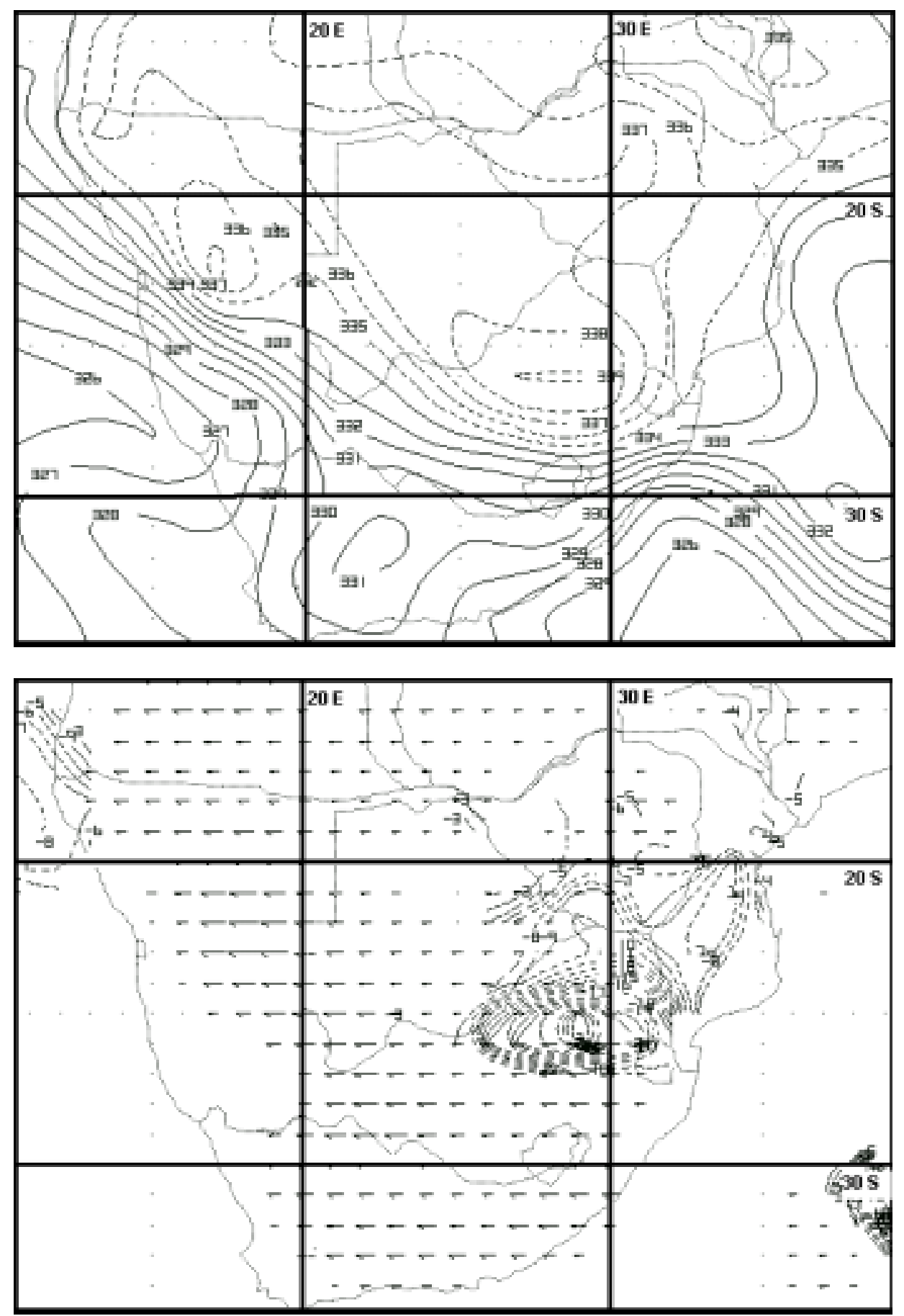

Figure 5

Average total static energy of the 850-300 hPa layer on 8 February 2000, in units of $10^{3} \mathrm{~J} \cdot \mathrm{kg}^{-1}$. Dashed lines indicate values greater than

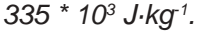

Figure 6

Areas of conditional instability (arrows) and upward motion from 700 to $400 \mathrm{hPa}$ (dashed lines). northern provinces of South Africa during the periods 5 to 10 and 22 to 25 February 2000. In the case study described in this paper MITS was effective in delineating areas where convective development will take place, resulting in rainfall between 1 and 100 $\mathrm{mm}$. MITS, however, tends to overestimate the area where convective rainfall is possible (Dyson, 2000). This indicates that some further fine-tuning may be required. However, delineating areas of probable convective rainfall over Southern Africa is at this point a very useful forecasting tool.

The five components of MITS are interactive features of the atmospheric dynamics and the MITS components may seem to possess a large degree of duplication. There are three reasons why this apparent duplication is allowed:
In the first place MITS is to be applied on NWP model prognoses. Good as these may be, they, nevertheless, remain approximations of reality. Neither the Eta model nor any other NWP model will always skilfully simulate all the atmospheric variables. In MITS five components are stipulated to identify a continental tropical weather system over South Africa. If one or more of the components is not implicitly met, the other components will still serve as an indication of the tropical nature of the atmospheric circulation. For this reason all five components of MITS are applied and not simply a single prognostic field such as vertical motion.

The second consideration is that MITS was developed for use in the operational environment by weather forecasters and it is 
MITS results for 8 February 2000. The blocks indicate the areas where convective development is predicted.

The shaded areas are observed rainfall.

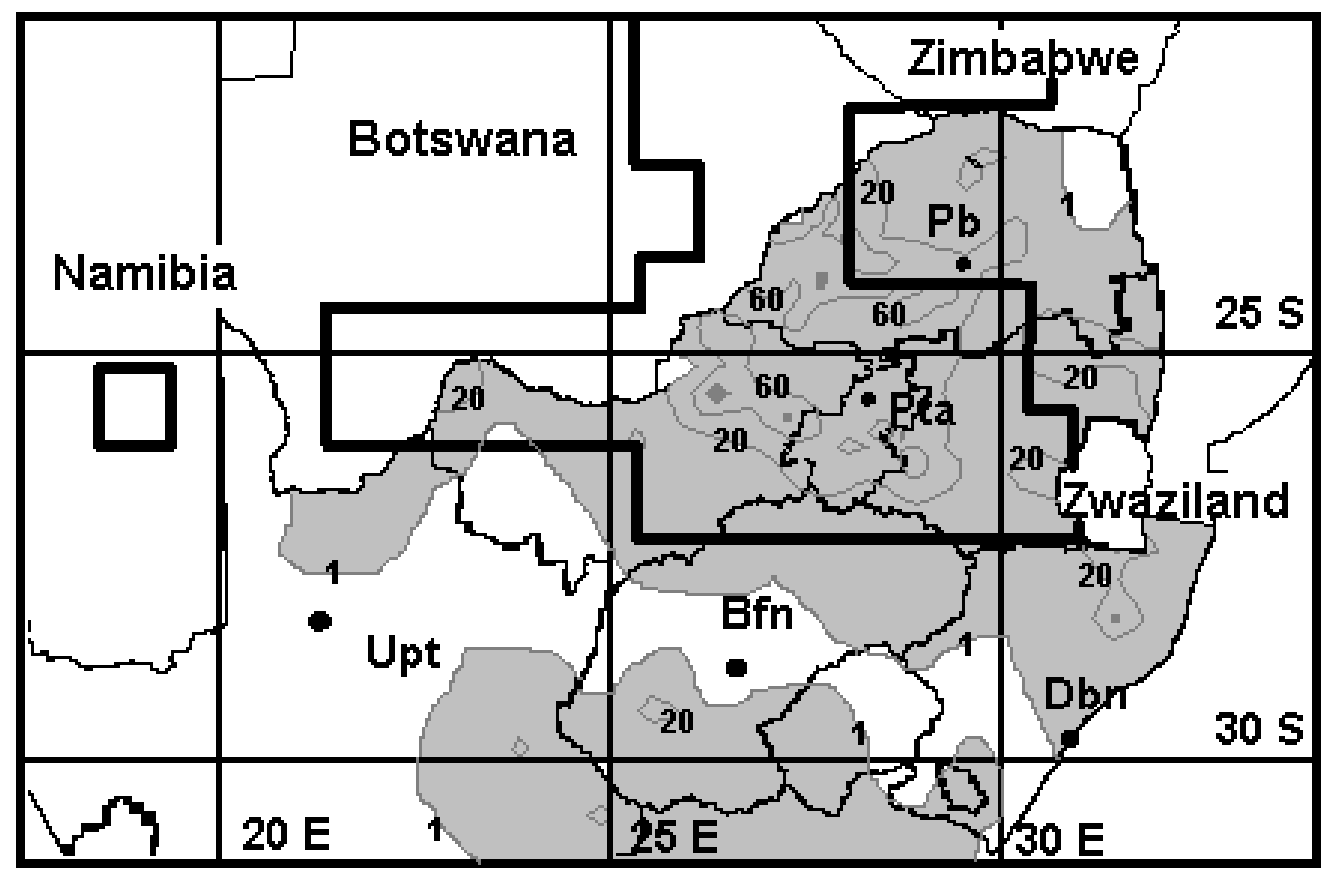

important to illustrate clearly the dynamic properties of a tropical atmosphere. Typically a $200 \mathrm{hPa}$ high is seen in the analysis somewhere over Southern Africa virtually each day and will necessarily be associated with above-normal column temperatures. However, only a few upper tropospheric highs can be considered tropical and develop because of latent heat release. MITS illustrates to the forecasters, using several components, that if this high is associated with high water vapour content, high values of TSE and conditional instability, then a tropical circulation system exists.

The third reason for the inclusion of all five components in MITS is to lead the forecaster step-by-step to the final component where a single field is generated which indicates areas where convective rainfall is probable. In this way the forecasters are reminded of the principles underlying the design of MITS, building confidence in the final result.

MITS was incorporated into the display package PCGRIDDS, in daily use by South African forecasters. MITS also proved to be an effective training tool. It promotes further investigation and understanding of the dynamic properties of tropical systems over Southern Africa. MITS identified parameters such as precipitable water, total static energy and conditional instability not previously used by forecasters in South Africa to identify tropical weather systems and the distribution of convective rainfall. MITS is available for implementation in the weather forecast offices of Southern Africa. Positive feedback for the further fine-tuning of the system could result in an effective regional tropical precipitation prediction tool. An operational evaluation system should also be developed in order to test the quality of the forecast provided by MITS.

\section{Acknowledgements}

The South African Water Research Commission Project No. K5/1011 deals with the early warning of heavy rainfall and its support is acknowledged. This paper forms part of ongoing research into the accurate forecasting of heavy rainfall over South Africa and the many suggestions and contributions by Mr E Poolman are greatly appreciated.

\section{References}

ALEXANDER WJR and VAN HEERDEN J (1991) Determination of the Risk of Widespread Interruption of Communications by Floods. Department of Transport Research Project RDAC 90/16.

CRIMP SJ, VAN DEN HEEVER SC, D'ABRETON PC, TYSON PD and MASON SJ (1997) Mesoscale Modelling of Tropical-Temperate Troughs and Associated Systems over Southern Africa. WRC Report 595/1/97, 395 pp.

DE CONING E (1997) Isentropic Analysis As A Forecasting Tool In South Africa. Unpublished M.Sc. Thesis, Univ. of Pretoria, S. Afr.

DYSON LL (2000) A Dynamical Forecasting Perspective on Synoptic Scale Weather Systems over southern Africa. Unpublished M.Sc. Thesis, Univ. of Pretoria, S. Afr.

DYSON LL and VAN HEERDEN J (2001) The heavy rainfall and floods over the northeastern interior of South Africa during February 2000. S. Afr. J. Sci. 97 80-86.

FORSDYKE AJ (1949) Weather forecasting in tropical regions. Geophys. Mem. 82 British Meteor. Office.

HARRISON MSJ (1988) Rainfall and precipitable water relationships over the central interior of South Africa. S. Afr. Geogr. J. 70 (2) 100-111.

HOLTON JR (1992) An Introduction to Dynamic Meteorology. Academic Press, San Diago. 511 pp.

HUSCHKE RE (1959) Glossary of Meteorology. Am. Meteorol. Soc. Boston. $638 \mathrm{pp}$.

KAROLY DJ and VINCENT DG (1998) Meteorology of the Southern Hemisphere 27 (49). Am. Meteorol. Soc. Boston. 410 pp.

LINDESAY JA and JURY MR (1991) Atmospheric controls and characteristics of a flood event in central South Africa. Int. J. of Clim. 11 609-627.

MESINGER F, JANJI Z NIKOVI S, GAVRILOV D and DEAVEN D (1988) The step-mountain coordinate: Model description and performance for cases of Alpine lee cyclogenesis and for a case of an Appalacian redevelopment. Monthly Weather Rev. 116 1493-1518.

POOLMAN EP (1999) Heavy rain events over South Africa. Preprints of the $15^{\text {th }}$ Anпи. Conf. of the S. Afr. Soc. Atmos. Sci.

PRESTON-WHITE RA and TYSON PD (1993) The Atmosphere and Weather of Southern Africa. Oxf. Univ. Press, Oxford. 374 pp.

RIEHL H (1979) Climate and Weather in the Tropics. Academic Press. $611 \mathrm{pp}$.

SCHULZE BR (1965) General Survey. Climate of South Africa. WB28. S. Afr. Weath. Serv., Private Bag X097, Pretoria 0001. 
TALJAARD JJ (1985) Cut-off lows in the South African region. S. Afr Weather Serv. Tech. Pap. 14, S. Afr. Weath. Serv., Private Bag X097, Pretoria, 0001. 153 pp.

TALJAARD JJ (1994) Atmospheric Circulation Systems, Synoptic Climatology and Weather Phenomena of South Africa. Part 1: Controls of the weather and climate of South Africa. S. Afr. Weath. Serv. Tech. Pap. 27, S. Afr. Weath. Serv., Private Bag X097, Pretoria, 0001. 45pp.
THOMPSON BW (1957) Some reflections on equatorial and tropical forecasting. East Africa Meteor. Dept. 7. 14 pp.

TRIEGAARDT DO, VAN HEERDEN J and STEYN PCL (1991) Anomalous precipitation and floods during February 1988. S. Afr. Weath. Serv. Tech. Paper 23, S. Afr. Weath. Serv., Private Bag X097, Pretoria 0001. 25 pp. 